\title{
Performance of super hybrid rice cultivars grown under no-tillage and direct seeding
}

\author{
Min Huang ${ }^{1}$, Yingbin Zou ${ }^{1}$, Peng Jiang ${ }^{1}$, Bing $X_{i a}{ }^{1}$, Anmin Xiao ${ }^{2}$
}

'Hunan Agricultural University/College of Agronomy 410128 - Changsha - China.

${ }^{2}$ Agricultural Bureau of Nanxian County - 413200 - Yiyang

- China.

*Corresponding author <ybzou123@126.com>

Edited by: Antonio Costa de Oliveira

Received April 14, 2011

Accepted September 29, 2011

\begin{abstract}
Good progress has been made in the super hybrid rice (Oryza sativa L.) breeding in China. However, rice yield not only depends on the genetic characteristics but also on the agronomic practices. No-tillage and direct seeding (NTDS) is a simplified cultivation technology that greatly simplifies both land preparation and crop establishment. Aiming to determine the grain yield performance of super hybrid rice under NTDS and to identify critical factors that determine grain yield, field experiments were conducted in Nanxian, Hunan Province, China in 2009 and 2010. Two super hybrid cultivars, Liangyoupeijiu and Y-liangyou 1, were grown under conventional tillage and transplanting (CTTP) and NTDS. Grain yield, yield components, biomass production, crop growth rate and biomass accumulation during sowing to heading (HD) and HD to maturity were measured for each cultivar. There was no difference in grain yield under NTDS and CTTP. However, grain yield differed with cultivar and year. Y-liangyou 1 produced $4 \%$ higher grain yield than Liangyoupeijiu in 2009, whereas in 2010 both cultivars yielded similarly. Grain yields of both cultivars were higher in 2009 than in 2010. Higher grain yield of Y-liangyou 1 in 2009 was associated with higher spikelet filling (spikelet filling percentage and grain weight), which resulted from higher biomass production. Crop growth rate after HD was critical for biomass production by the super hybrid rice. We suggest that increasing the crop growth rate after $\mathrm{HD}$ is an effective approach to increase grain yield of super hybrid rice under NTDS.

Keywords: rice cultivation technologies, grain yield comparison, yield formation characteristics
\end{abstract}

\section{Introduction}

Rice (Oryza sativa L.) is the staple food crop in China and its productivity is critical for national food security. To further increase the rice yield potential, China established a nationwide mega-project in 1996 on the development of a super rice based on the ideotype concept (Cheng et al., 1998). By 2007, 61 cultivars with high yield potential were approved as super rice by the Ministry of Agriculture of China (Huang and Zou, 2009). However, rice yield not only depends upon the genetics but also on the agronomic practices (Zou et al., 2003). In recent year, simplified cultivation technologies for rice have become increasingly attractive in China because of their social, economical and environmental benefits (Huang et al., 2011).

No-tillage and direct seeding (NTDS) is a simplified cultivation technology that greatly diminishes both land preparation and crop establishment operations (Huang et al., 2011). There have been reports evaluating the application of NTDS in rice production (Cho et al., 2001; Singh et al., 2001; Bhushan et al., 2007). However, in these studies the emphasis has been on the systems productivity, while not much attention has been focused on the crop, and the rice cultivars used have been common hybrids or inbreds, and limited information is available on the super hybrid rice.

Rice yield is determined by the sink size (spikelets per unit land area), spikelet filling percentage and grain weight. Sink size is considered as the primary determinant of the rice yield (Kropff et al., 1994). In another approach, rice yield is determined by biomass production and harvest index (Yang et al., 2008). Achieving higher rice yield depended on increasing the biomass production, because there was little scope to further increase the harvest index (Evans and Fischer, 1999). Biomass production can be increased by increasing growth duration or crop growth rate or both (Yoshida, 1983). Zhang et al. (2009) reported that longer growth duration was partly responsible for higher biomass production by super hybrid rice.

In the present study, we compared grain yield and yield components, and biomass production by super hybrid rice under NTDS and traditional cultivation method. The specific objectives of this study were (1) to determine the grain yield performance of the super hybrid rice under the NTDS and (2) to identify the critical factors that determine the grain yield of the super hybrid rice under the NTDS.

\section{Materials and Methods}

Field experiments were conducted in Nanxian $\left(29^{\circ} 21^{\prime} \mathrm{N}, 112^{\circ} 25^{\prime} \mathrm{E}, 30 \mathrm{~m}\right.$ asl), Hunan Province, China in 2009 and 2010. The experimental site has a moist subtropical monsoon climate. The soil at the experimental paddy field was a purple calcareous clayey (Fluvisols, FAO taxonomy) with $\mathrm{pH}$ of 7.83 , organic matter of 24.2 $\mathrm{g} \mathrm{kg}^{-1}$, total $\mathrm{N}$ of $1.10 \mathrm{~g} \mathrm{~kg}^{-1}$, and available $\mathrm{P}, \mathrm{K}, \mathrm{Ca}, \mathrm{Mg}$, $\mathrm{Fe}, \mathrm{Mn}, \mathrm{Cu}, \mathrm{SiO}_{2}, \mathrm{~S}$ and $\mathrm{B}$ of $14.8,80.1,1640,139,48.4$, $13.7,5.26,525,88.1$ and $0.216 \mathrm{mg} \mathrm{kg}^{-1}$, respectively. The $\mathrm{pH}$ was determined by digital $\mathrm{pH}$ meter, organic matter by potassium dichromate method, total $\mathrm{N}$ by semi-micro Kjeldahl method, available $\mathrm{P}$ by Olsen method, available 
$\mathrm{K}, \mathrm{Ca}, \mathrm{Mg}, \mathrm{Fe}, \mathrm{Mn}$ and $\mathrm{Cu}$ by atomic absorption spectrophotometry, available $\mathrm{SiO}_{2}$ by silicon-molybdenum blue colorimetry, available $S$ by turbidimetric method, and available B by curcumin colorimetric method.

Two super hybrid rice cultivars Liangyoupeijiu and Y-liangyou 1 were used in the study. Liangyoupeijiu is an indica-japonica hybrid (Peiai64S $\times 9311$ ) released in 1999; and Y-liangyou 1 is an indica hybrid (Y58S $\times$ 9311) released in 2006 . These two cultivars are widely grown by rice farmers in China.

Each year, Liangyoupeijiu and Y-liangyou 1 were grown under the traditional method (conventional tillage and transplanting, CTTP) and NTDS after harvest of oilseed rape, which was also grown under NTDS. Plots were laid out in a randomized complete block design with four replications, using a plot size of $30 \mathrm{~m}^{2}(12 \mathrm{~m} \times$ $2.5 \mathrm{~m})$. The land preparation of the plots under the conventional tillage was carried out by plowing, followed by two harrowings; and for the plots under no-tillage, herbicide paraquat $20 \%$ was used (diluted $5 \mathrm{~mL} \mathrm{~L}^{-1}$ and applied at $750 \mathrm{~L} \mathrm{ha}^{-1}$ ) seven days before sowing. Seeds were first sterilized by soaking in $0.3 \%$ trichloroisocyanuric acid solution for $12 \mathrm{~h}$, and then washed and soaked in tap water for $24 \mathrm{~h}$ at room temperature. Soaked seeds were kept between thick layers of cotton cloth and allowed to germinate at room temperature. For transplanting, seedlings were raised in nursery beds, and twenty five-day-old seedlings were manually transplanted at a spacing of $20 \mathrm{~cm} \times 20 \mathrm{~cm}$ with one seedling per hill on 16 June in 2009 and on 18 June in 2010. For direct seeding, the pre-germinated seeds were manually broadcast onto the soil surface at a seed rate of $22.5 \mathrm{~kg} \mathrm{ha}^{-1}$ (about 120 seeds $\mathrm{m}^{-2}$ ) on 20 May in 2009 and 22 May in 2010. Urea was used as a source of $\mathrm{N}$, single superphosphate of $\mathrm{P}$ and potassium chloride of $\mathrm{K}$ with rates of $150 \mathrm{~kg}$ $\mathrm{N} \mathrm{ha}^{-1}, 90 \mathrm{~kg} \mathrm{P}_{2} \mathrm{O}_{5} \mathrm{ha}^{-1}$ and $180 \mathrm{~kg} \mathrm{~K}_{2} \mathrm{O} \mathrm{ha}{ }^{-1}$. Nitrogen was split-applied: $90 \mathrm{~kg} \mathrm{ha}^{-1}$ as basal application, $45 \mathrm{~kg}$ $\mathrm{ha}^{-1}$ at mid-tillering, and $15 \mathrm{~kg} \mathrm{ha}^{-1}$ at panicle initiation. Phosphorus was applied as basal and $\mathrm{K}$ was split equally as basal application and at panicle initiation. Water management adopted a strategy of flooding-midseason drainage-reflooding-moist intermittent irrigation. Weeds, insects and diseases were controlled by applying herbicide (cyhalofop-butyl $10 \%$ EC diluted $2 \mathrm{~mL} \mathrm{~L}^{-1}$ and applied at $600 \mathrm{~L} \mathrm{ha}^{-1}$ at 4 leaves unfolded stage for rice plants), insecticides and fungicides.

Plants were sampled from $0.48-\mathrm{m}^{2}$ areas for each plot at heading (HD) and maturity (MA). At HD, plant samples were oven-dried at $70{ }^{\circ} \mathrm{C}$ to constant wt for biomass evaluation. At MA, plant samples were separated into straw (including rachis) and grain, and the panicle number was counted to determine panicles per $\mathrm{m}^{2}$. Panicles were hand-threshed, and filled spikelets were separated from unfilled ones by submertion in tap water. Three subsamples of $30 \mathrm{~g}$ of filled spikelets and all unfilled spikelets were taken to count the number of spikelets. Spikelets per panicle, spikelet filling percentage and grain weight were calculated. Aboveground bio- mass was the total dry matter of straw and filled and unfilled spikelets. Harvest index was calculated as the ratio of filled grain dry weight to total aboveground biomass. Crop growth rate was calculated according to Watson (1952) and was expressed in $\mathrm{g} \mathrm{m}^{-2} \mathrm{~d}^{-1}$. Grain yield was determined from the harvested plants in $5-\mathrm{m}^{2}$ areas for each plot and adjusted to the standard water content of $0.14 \mathrm{~g} \mathrm{H}_{2} \mathrm{O} \mathrm{g}^{-1}$.

Statistical analysis of the data was performed using analysis of variance (General AOV/AOCV procedure, Statistix 8, Analytical Software, Tallahassee, FL, USA).

\section{Results and Discussion}

The difference in grain yield between CTTP and NTDS was not significant ( $p>0.05$; Table 1). Mean grain yields across cultivars and years were $9.34 \mathrm{t} \mathrm{ha}^{-1}$ for CTTP and $9.23 \mathrm{t} \mathrm{ha}^{-1}$ for NTDS. However, grain yield differed with cultivar $(p<0.05)$ and year $(p<0.01)$. In 2009, Y-liangyou 1 produced $0.43 \mathrm{t} \mathrm{ha}^{-1}(4 \%)$ higher grain yield than Liangyoupeijiu, whereas in 2010 both cultivars yielded similarly. In general, grain yields of both cultivars were higher in 2009 than in 2010. In 2009, grain yields were ranging from 9.61 to $10.24 \mathrm{t} \mathrm{ha}^{-1}$, whereas in 2010 they varied from 8.46 to $8.77 \mathrm{t} \mathrm{ha}^{-1}$. The grain yield difference between years was partly attributed to the variation in temperature over the year. Averaged across cultivation methods and cultivars, mean daily maximum temperature after HD was $1.8^{\circ} \mathrm{C}$ higher in 2009 than in 2010 (Figure 1A), while the difference in mean daily minimum temperature between the two years was as small as $0.4^{\circ} \mathrm{C}$ (Figure 1B).

There were differences in panicles per $\mathrm{m}^{2}$ and spikelets per panicle between CTTP and NTDS $p<$ 0.01; Table 1). Averaged across two cultivars and two years, panicles per $\mathrm{m}^{2}$ under NTDS were $20 \%$ more than under CTTP, while spikelets per panicle were 19 $\%$ lower under NTDS than CTTP. These was a strong compensation between panicles per $\mathrm{m}^{2}$ and spikelets per panicle. In cereal crops, the compensation among yield components always arises (Nickell and Grafius, 1969; Heinrich et al., 1983; Simane et al., 1993; Zeng and Shannon, 2000), either from the physiological competition or from the developmental allometry (Grafius et al., 1976; Grafius, 1978), and it has been held to largely contribute to the failure in breeding efforts to improve yield potential through indirect selection for yield components in cereals ( $\mathrm{Li}$ et al., 1998). In the present study, the compensation between panicles per $\mathrm{m}^{2}$ and spikelets per panicle was not significant for spikelets per $\mathrm{m}^{2}$ between CTTP and NTDS. An increase in panicle number per unit land area or spikelets per panicle would not necessarily result in an overall increase in the sink size because of a strong compensation mechanism between the two components (Ying et al., 1998).

The differences in spikelet filling percentage and grain weight between CTTP and NTDS were not significant $(p>0.05 ;$ Table 1$)$. However, both the components 
Table 1 - Grain yield, yield components, total aboveground biomass and harvest index of super hybrid rice Liangyoupeijiu and Y-liangyou 1 grown under conventional tillage and transplanting (CTTP) and no-tillage and direct seeding (NTDS) in Nanxian, Hunan Province, China in 2009 and 2010.

\begin{tabular}{|c|c|c|c|c|c|c|c|c|c|c|}
\hline Year & Cultivar & $\begin{array}{l}\text { Cultivation } \\
\text { method }\end{array}$ & Grain yield & $\begin{array}{c}\text { Panicles per } \\
\mathrm{m}^{2}\end{array}$ & $\begin{array}{l}\text { Spikelets per } \\
\text { panicle }\end{array}$ & $\begin{array}{c}\text { Spikelets per } \\
\mathrm{m}^{2} \\
\left(\times 10^{3}\right)\end{array}$ & $\begin{array}{l}\text { Spikelet } \\
\text { filling }\end{array}$ & $\begin{array}{c}\text { Grain } \\
\text { weight }\end{array}$ & $\begin{array}{c}\text { Total above ground } \\
\text { biomass }\end{array}$ & $\begin{array}{l}\text { Harvest } \\
\text { index }\end{array}$ \\
\hline & & & t ha $^{-1}$ & & & & $\%$ & $\mathrm{mg}$ & $\mathrm{g} \mathrm{m}^{-2}$ & $\%$ \\
\hline \multirow[t]{4}{*}{2009} & Liangyoupeijiu & CTTP & 9.61 & 222 & 208 & 45.8 & 80.5 & 24.9 & 1866 & 49.6 \\
\hline & & NTDS & 9.85 & 291 & 159 & 46.2 & 81.4 & 24.7 & 1918 & 48.5 \\
\hline & Y-liangyou 1 & CTTP & 10.24 & 241 & 196 & 47.0 & 85.3 & 25.6 & 2354 & 43.8 \\
\hline & & NTDS & 10.07 & 309 & 146 & 45.4 & 89.0 & 24.7 & 2324 & 42.7 \\
\hline \multirow[t]{4}{*}{2010} & Liangyoupeijiu & CTTP & 8.77 & 219 & 212 & 46.4 & 77.7 & 23.4 & 1706 & 49.5 \\
\hline & & NTDS & 8.46 & 253 & 176 & 43.8 & 78.9 & 23.7 & 1642 & 50.8 \\
\hline & Y-liangyou 1 & CTTP & 8.75 & 226 & 223 & 50.4 & 82.6 & 21.1 & 1827 & 48.1 \\
\hline & & NTDS & 8.52 & 240 & 197 & 47.1 & 84.0 & 21.2 & 1702 & 49.5 \\
\hline \multicolumn{11}{|c|}{ Analysis of variance } \\
\hline \multicolumn{3}{|c|}{ Cultivation method } & NS & ** & * * & NS & NS & NS & NS & NS \\
\hline \multicolumn{3}{|c|}{ Cultivar } & * & NS & NS & NS & * * & * * & * & ** \\
\hline \multicolumn{3}{|c|}{ Cultivation method $\times$ Cultivar } & NS & NS & NS & NS & NS & * & NS & NS \\
\hline \multicolumn{3}{|c|}{ Cultivation method $\times$ Year } & NS & NS & NS & NS & NS & ** & NS & NS \\
\hline \multicolumn{3}{|c|}{ Cultivar $\times$ Year } & * & NS & NS & NS & NS & * * & NS & NS \\
\hline \multicolumn{3}{|c|}{ Cultivation method $\times$ Cultivar $\times$ Year } & NS & NS & NS & NS & NS & NS & NS & NS \\
\hline
\end{tabular}

*Significance at 0.05. ${ }^{* *}$ Significance at 0.01. NS denotes non-significance.
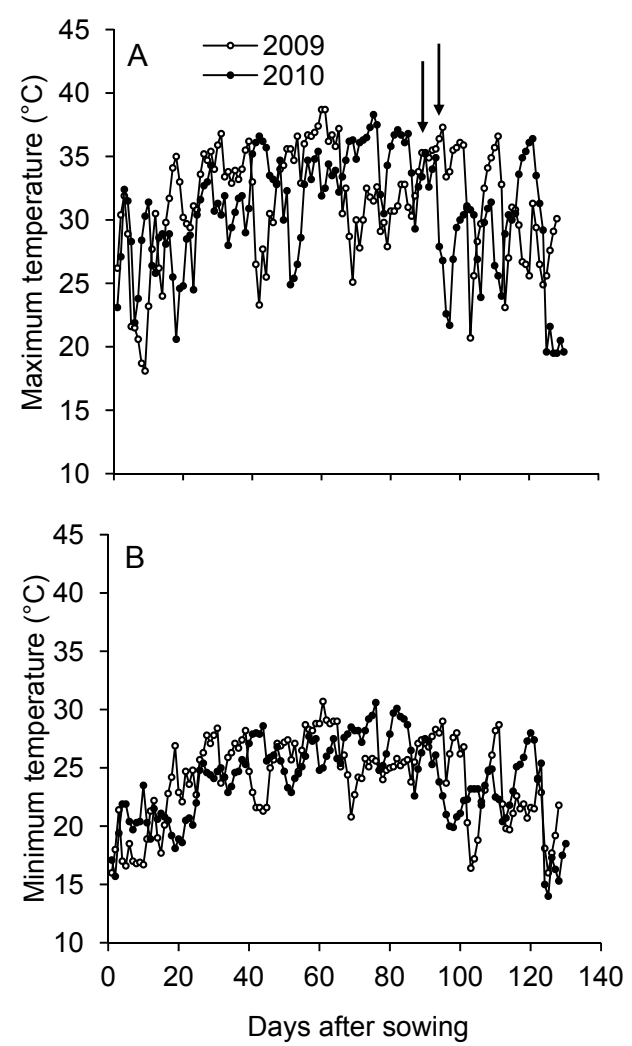

Figure 1 - Daily maximum (A) and minimum (B) temperatures during rice growing season in Nanxian, Hunan Province, China in 2009 and 2010. Two arrows indicate the earliest and latest heading dates. were variable across cultivars $(p<0.01)$ and years $(p$ $<0.05$ or $p<0.01$ ). Y-liangyou 1 produced the highest spikelet filling percentage of $89 \%$ under NTDS in 2009 , while Liangyoupeijiu produced the lowest spikelet filling percentage of 77 under CTTP in 2010. In general, the spikelet filling percentage was higher in Y-liangyou 1 than in Liangyoupeijiu, and was higher in 2009 than in 2010. There was no consistent varietal difference in grain weight, however, a consistent difference was observed between years. Grain weight was higher in 2009 than in 2010, especially for Y-liangyou 1. No difference was observed in total aboveground biomass between CTTP and NTDS ( $p>0.05)$, whereas difference was noted both between cultivars $(p<0.05)$ and between years $(p<0.01$; Table 1$)$. Generally, total aboveground biomass was higher in Y-liangyou 1 than in Liangyoupeijiu, and was higher in 2009 than in 2010. These results, in agreement with previous reports (Lu et al., 1994; Yuan, 1994), indicated that poor spikelet filling was a result of low source capacity. It is commonly accepted that super hybrid cultivars have more spikelets per panicle than ordinary hybrid and inbred cultivars, which result in more spikelets per $\mathrm{m}^{2}$ (Zhu et al., 2002; Peng et al., 2008; Zhang et al., 2009). Therefore, the source capacity should be emphasized to match the large sink size in super hybrid rice production, although source-sink relations were well balanced in China's super hybrid rice breeding project by improving photosynthesis and delaying leaf senescence of the top three leaves during the ripening phase (Peng et al., 2008).

There was no difference in the harvest index between CTTP and NTDS $(p>0.05)$, whereas differenc- 
es were observed both between cultivars $(p<0.01)$ and between years $(p<0.05$; Table 1$)$. In general, the harvest index was higher for Liangyoupeijiu than for Y-liangyou 1, and was higher in 2010 than in 2009. This was in contrast to the grain and aboveground biomass yield of the cultivars (Table 1). It is not clear as to whether biomass production or harvest index should be emphasized to further improve rice yield. Some investigators reported that high grain yield of rice was achieved mainly due to the increase in harvest index (Takeda et al., 1983; Evans et al., 1984), whereas a number of crop physiologists suggested that further improvement in rice yield might be driven from the increased biomass production rather than harvest index (Akita, 1989; Evans and Fischer, 1999; Peng et al., 1999). The results of the present study support the later hypothesis.

Averaged across cultivars and years, the growth duration from sowing (SO) to HD was $4 \mathrm{~d}$ shorter under NTDS than under CTTP, while the growth duration from HD to MA was similar between the two cultivation methods (Figure 2A). The former could be explained by the growth process under direct seeding without the setback caused by uprooting and transplanting (Nabheerong, 1993; Kotera et al., 2004). The growth duration from SO to HD and from HD to MA were similar both between cultivars and between years. On the other hand, there were no differences in crop growth rate from SO to HD and from HD to MA between CTTP and NTDS $(p>$ $0.05)$, while differences were observed in crop growth rate from HD to MA between the cultivars in 2009 (p $<0.01)$ and between years for Y-liangyou 1 ( $p<0.01$; Figure 2B). During HD to MA, Y-liangyou 1 had a maximum crop growth rate of $30.5 \mathrm{~g} \mathrm{~m}^{-2} \mathrm{~d}^{-1}$ under NTDS in 2009. Also, similar to crop growth rate, differences in the aboveground biomass accumulation were only found after HD between cultivars in $2009(p<0.01)$ and between years for Y-liangyou 1 ( $p<0.01$; Figure 2C). During this growth period, Y-liangyou 1 produced a maximum aboveground biomass of $1,008 \mathrm{~g} \mathrm{~m}^{-2}$ under NTDS in 2009. It was apparent that the crop growth rate after HD was the critical factor that determined the aboveground biomass in super hybrid rice. We suggest that increasing the crop growth rate after HD is an effective approach to increase grain yield of super hybrid rice under NTDS.

\section{Acknowledgements}

The financial support of this study was provided by the Ministry of Agriculture of China.

\section{References}

Akita, S. 1989. Improving yield potential in tropical rice. p. 41-73. In: International Rice Research Institute. Progress in irrigated rice research. International Rice Research Institute, Los Baños, Philippines.
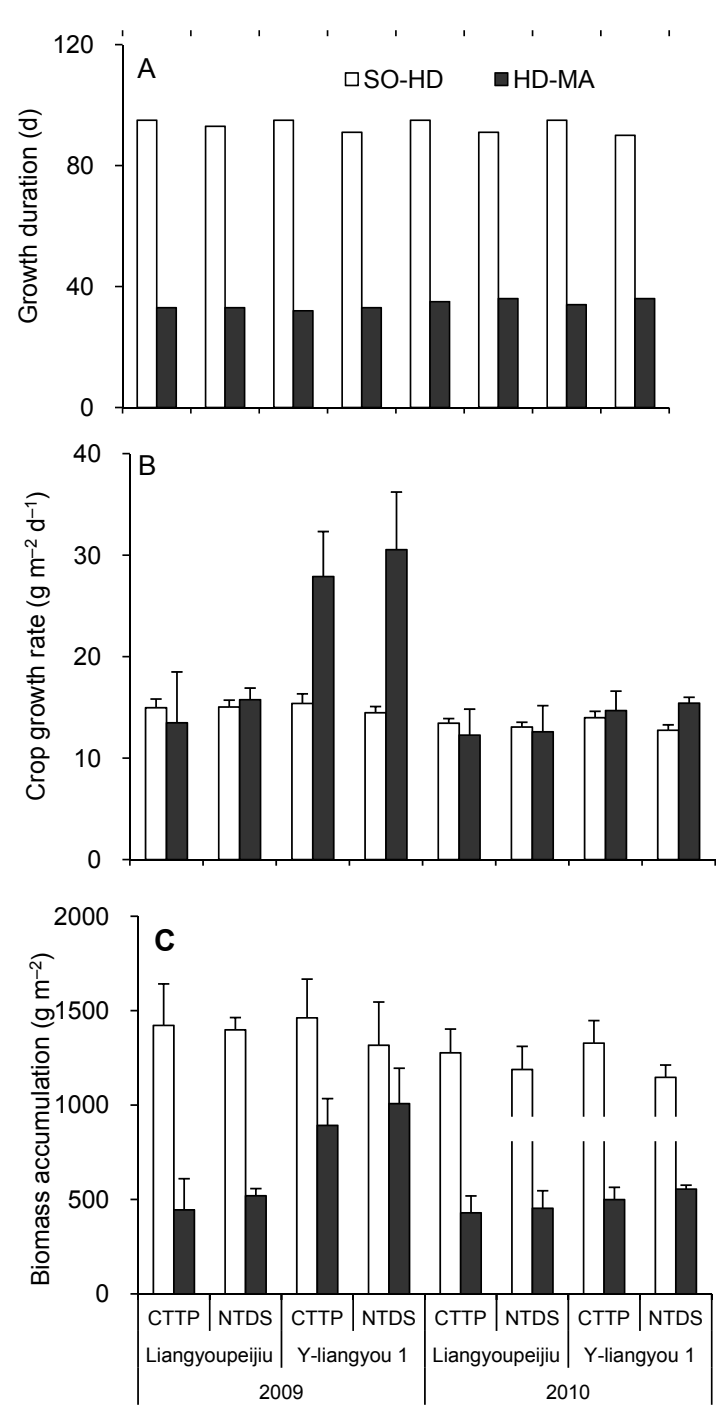

Figure 2 - Growth duration (A), crop growth rate (B) and aboveground biomass accumulation $(C)$ from sowing $(\mathrm{SO})$ to heading $(\mathrm{HD})$ and from HD to maturity (MA) of super hybrid rice Liangyoupeijiu and Y-liangyou 1 grown under conventional tillage and transplanting (CTTP) and no-tillage and direct seeding (NTDS) in Nanxian, Hunan Province, China in 2009 and 2010.

Bhushan, L.; Ladha, J.K.; Gupta, R.K.; Singh, S.; Tirol-Padre, A.; Saharawat, Y.S.; Gathala, M.; Pathak, H. 2007. Saving of water and labor in a rice-wheat system with no-tillage and direct seeding technologies. Agronomy Journal 99: 12881296.

Cheng, S.; Liao, X.; Min, S. 1998. China's super rice research: background, goals and issues. China Rice 1: 3-5 (in Chinese, with abstract in English).

Cho, Y.S.; Lee, B.Z.; Choe, Z.R.; Ockerby, S.E. 2001. An evaluation of a no-tillage, unfertilised, direct-sown, wheat-rice cropping system in Korea. Australian Journal of Experimental Agriculture 41: 53-60.

Evans, L.T.; Fischer, R.A. 1999. Yield potential: its definition, measurement, and significance. Crop Science 39: 1544-1551. 
Evans, L.T.; Visperas, R.M.; Vergara, B.S. 1984. Morphological and physiological changes among rice varieties used in the Philippines over the last seventy years. Field Crops Research 8: 105-125.

Grafius, J.E. 1978. Multiple characters and correlated response. Crop Science 18: 931-934.

Grafius, J.E.; Thomas, R.T.; Barnard, J. 1976. Effect of parental component complementation on yield and components of yield in barley. Crop Science 16: 673-677.

Heinrich, G.M.; Francis, C.A.; Eastin, J.D. 1983. Stability of grain sorghum yield components across diverse environments. Crop Science 23: 209-212.

Huang, M.; Ibrahim, Md.; Xia, B.; Zou, Y. 2011. Significance, progress and prospects for research in simplified cultivation technologies for rice in China. Journal of Agricultural Science 149: 487-496.

Huang, M.; Zou, Y.B. 2009. Comparison of grain filling characteristics between two super rice cultivars with remarkable difference in grain weight. World Applied Sciences Journal 6: 674-679.

Kotera, A.; Nawata, E.; Chuong, P.V.; Giao, N.N.; Sakuratani, T. 2004. A model for phenological development of Vietnamese rice influenced by transplanting shock. Plant Production Science 7: 62-69.

Kropff, M.J.; Cassman, K.G.; Peng, S.; Matthews, R.B.; Setter, T.L. 1994. Quantitative understanding of yield potential. p. 21-38. In: Cassman, K.G., ed. Breaking the yield barrier. International Rice Research Institute, Los Baños, Philippines.

Li, Z.; Pinson, S.R.M.; Stansel, J.W.; Paterson, A.H. 1998. Genetic dissection of the source-sink relationship affecting fecundity and yield in rice (Oryza sativa L.). Molecular Breeding 4: 419426.

Lu, X.; Zhang, Z.; Virmani, S.S. 1994. Breeding status quo of two-line system hybrid rice. Chinese Journal of Rice Science 8: 48-54.

Nabheerong, N. 1993. Root growth and nutrient uptake of rice as affected by planting methods and green manures. Kasetsart Journal 27: 358-368.

Nickell, C.D.; Grafius, J.E. 1969. Analysis of a negative response to selection for high yield in winter barley, Hordeum valgare L. Crop Science 9: 447-451.

Peng, S.; Cassman, K.G.; Virmani, S.S.; Sheehy, J.E.; Khush, G.S. 1999. Yield potential trends of tropical rice since release of IR8 and the challenge of increasing rice yield potential. Crop Science 39: 1552-1559.

Peng, S.; Khush, G.S.; Virk, P.; Tang, Q.; Zou, Y. 2008. Progress in ideotype breeding to increase rice yield potential. Field Crops Research 108: 32-38.
Simane, B.; Struik, P.C.; Nachit, M.M.; Peacock, J.M. 1993. Ontogenetic analysis of yield components and yield stability of durum wheat in water-limited environments. Euphytica 71: 211-219.

Singh, S.; Sharma, S.N.; Prasad, R. 2001. The effect of seeding and tillage methods on productivity of rice-wheat cropping system. Soil and Tillage Research 61: 125-131.

Takeda, T.M.; Oka, M.; Agata, W. 1983. Studies on the dry matter and grain production of rice cultivars in the warm area of Japan: I. Comparison of the dry matter production between old and new types of rice cultivars. Japanese Journal of Crop Science 52: 299-306.

Watson, D.J. 1952. The physiological basis of variation in yield. Annual Review of Plant Physiology 23: 437-464.

Yang, W.; Peng, S.; Laza, R.C.; Visperas, R.M.; Dionisio-Sese, M.L. 2008. Yield gap analysis between dry and wet season rice crop grown under high-yielding management conditions. Agronomy Journal 100: 1390-1395.

Ying, J.; Peng, S.; He, Q.; Yang, H.; Yang, C.; Visperas, R.M.; Cassman, K.G. 1998. Comparison of high-yield rice in tropical and subtropical environments I. Determinants of grain and dry matter yields. Field Crops Research 57: 71-84.

Yoshida, S. 1983. Rice. p. 103-127. In: Smith, W.H.; Banta, S.J., eds. Potential productivity of field crops under different environments. International Rice Research Institute, Los Baños, Philippines.

Yuan, L.P. 1994. Increasing yield potential in rice by exploitation of heterosis. p. 1-6. In: Virmani S.S., ed. Hybrid rice technology: new developments and future prospects. International Rice Research Institute, Los Baños, Philippines.

Zeng, L.; Shannon, M.C. 2000. Effects of salinity on grain yield and yield components of rice at different seeding densities. Agronomy Journal 92: 418-423.

Zhang, Y.; Tang, Q.; Zou, Y.; Li, D.; Qin, J.; Yang, S.; Chen, L.; Xia, B.; Peng, S. 2009. Yield potential and radiation use efficiency of "super" hybrid rice grown under subtropical conditions. Field Crops Research 114: 91-98.

Zhu, D.; Lin, X.; Chen, W.; Sun, Y.; Lu, W.; Duan, B.; Zhang, Y. 2002. Nutritional characteristics and fertilizer management strategies for super rice variety Xieyou 9308. China Rice 2: 18-19 (in Chinese, with abstract in English).

Zou, Y.B.; Zhou, S.Y.; Tang, Q.Y. 2003. Status and prospect of high yielding cultivation researches on China super hybrid rice. Journal of Hunan Agricultural University 29: 78-84. 